\title{
Stefano Zaffagnini: Associate Editor
}

\author{
Jon Karlsson • Rene Verdonk • Roland Becker • \\ Neil Thomas
}

Published online: 19 October 2011

(C) Springer-Verlag 2011

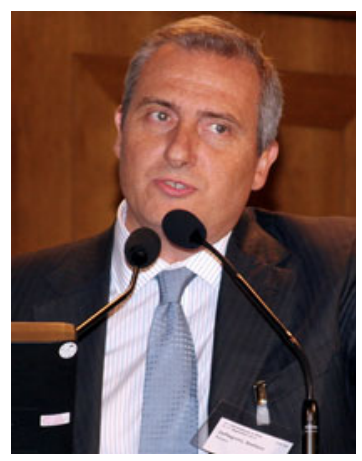

Stefano Zaffagnini, MD, has been appointed an Associate Editor of the Knee Surgery Sports Traumatology and Arthroscopy Journal commencing January 2012.

Stefano has served the journal for several years both as a reviewer and an Editorial Board Member.

He trained at the University of Bologna in Italy, graduating in 1987. He then worked at the Istituto Ortopedico

\footnotetext{
J. Karlsson ( $\square)$

Department of Orthopaedics, Sahlgrenska University Hospital, Gothenburg, Sweden

e-mail: jon.kssta@gmail.com

R. Verdonk

Department of Orthopaedics and Traumatology,

Ghent State University, Ghent, Belgium

R. Becker

Department of Orthopaedic and Traumatology,

City Hospital Brandenburg, Hochstrasse 29,
}

14770 Havel, Brandenburg, Germany

Rizzoli at the University under the leadership of Prof. Marcacci and Prof. Marchetti finishing his specialist training in Orthopaedics and Traumatology in 1992.

In 1994, he spent 6 months in a sports medicine fellowship with Prof. Fu and Prof. Woo at the UPMC Hospital in Pittsburgh (USA). Then, in 1996, he became consultant for knee surgery and arthroscopy at the Istituto Ortopedico Rizzoli in Bologna and the following year was selected for the AOSSM-ESSKA Sports Medicine Travelling Fellowship.

His research work focuses on anatomy and biomechanics of the ACL, navigation in knee surgery (soft tissue as well as knee replacement), surgical techniques of ACL reconstruction, meniscus, and cartilage transplantation.

Since 2008, he has been the Chief Consultant for knee surgery and arthroscopy at the Center for Sports Traumatology at the Istituto Ortopedico Rizzoli and University Researcher at Bologna University.

Stefano has been a member of ESSKA since 1994 and has been active in the following roles: past member of the ESSKA cartilage committee (2006-2008), past president of the ESSKA Arthroscopy Committee (2008-2010), and program co-chairman of the next ESSKA Congress (Geneve 2012). He is also a member of ISAKOS, co-chair of the ISAKOS scientific committee, $2^{\text {nd }}$ vice president of the Italian Knee Society (SIGASCOT), member of the Italian Arthroscopy Society, the ACL Study Group, Honorary member of the AOSSM, and International member of the AAOS. In 2010, he was appointed an Associate Professor at the Bologna University.

We welcome Stefano to the team of Editors of KSSTA.

\section{N. Thomas}

Winchester, UK 